\title{
The Impact of Drought: A Study Based on Anuradhapra District in Sri Lanka
}

\author{
Kaleel.MIM ${ }^{1}$, Nijamir.K ${ }^{2}$ \\ Department of Geography, South Eastern University of Sri Lanka, Oluvil
}

\begin{abstract}
Anuradhapura District being one of the paddy providers in Sri Lanka highly affected due to the drought disaster. The trend and cause for the drought should be identified for future remedial measures. Thus this study is conducted based on the following objective. The primary objective is that identifying the impact of drought in Anuradhapura District' and the secondary objective are finding the direct and indirect factors causing drought and the influence of drought in agriculture in the study area and proposing suggestions to lessen the impact of drought in the study area. To attain these objectives data from 1900 to 2014 were collected. All the data were analysed and the trend of drought, condition of drought and the impact of drought were identified. Many suggestions have been provided in the suggestion part.
\end{abstract}

Keywords-drought, disaster, agriculture, impact.

\section{INTRODUCTION}

Drought is an extended period of unusually dry weather when there is not enough rain. The lack of precipitation can cause a variety of problems for local communities, including damage to crops and a shortage of drinking water. These effects can lead to devastating economic and social disasters, such as famine, forced migration away from drought-stricken areas, and conflict over remaining resources (National Geography, 2017).

The drought disaster, frequently strike Sri Lanka is a serious problem to the nation. Most of the districts are being experienced by drought in Sri Lanka. Loss of agriculture and economy are evidences for the strike of drought in Sri Lanka. Many Districts in Sri Lanka are facing drought problems. Anuradhapura District, called as "the heart of Sri Lanka's rice bowl" one of the paddy providers to the nation is being severely affected due to the drought occurrence.

Anuradhapura District receives rainfall from northeast monsoon. The annual rainfall ranges from $1250 \mathrm{~mm}-$ $2000 \mathrm{~mm}$ from northeast monsoon. Increasing evaporation causes many dryland in Anuradhapura District. Small ponds, streams and other small-scale water bodies are highly affected where much amount of paddy cultivated using these water bodies.

Due to the severe drought many places 14 Divisional secretaries are highly affected due to the drought disaster in Anuradhapura Districts: Horovapothana, Ipolagama, Nuwaragampalatha, Rambewa, Thirappana, Nachchathuwa, Palugaswewa, Kekirawa, Kahalkasthikiliya, Thambuthegama, Pathaviya, Madavachchi and Kepatikollawa are the Divisional Secretariats, highly affected.

The impact of the drought occurrence should be controlled to pave a way for the agriculture and for the socio economic development of inhabitants in Anuradhapura.

\section{STUDY AREA}

Anuradhpura District is situated in the dry zone of Sri Lanka in the north central province of Sri Lanka. It has 22 Divisional Secretariat Divisions combined by 694 GramaNiladhary Division. It has 886945 total population of 2387769 families. The boundaries of Anuradhapura are in north Vavuniya District, in east Trincomalee District, in South Mattale District and in the west Puttalam District. Paddy is one of the major incomes of the inhabitants of Anuradhapura District. Fishery, industries, business activities and service sectors are other sources for the income.

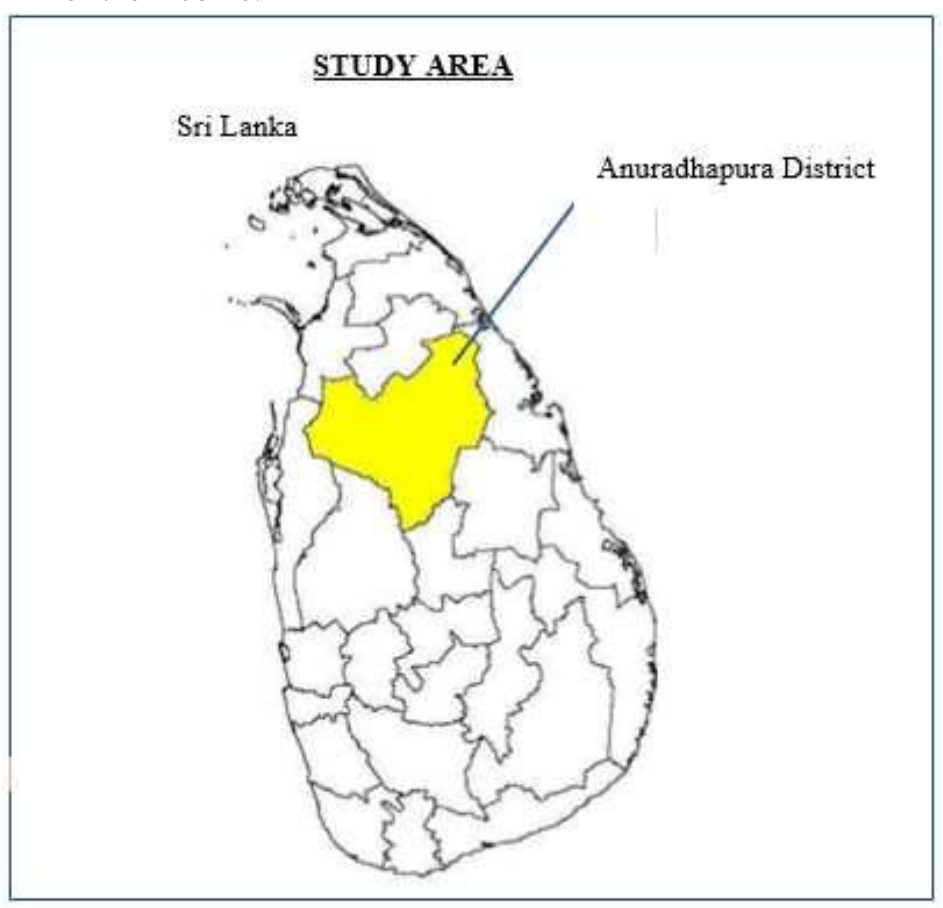

Retrieved from: ArcGIS10.1 


\section{OBJECTIVES}

Primary objective

- Identifying the impact of drought in Anuradhapura District

\section{Secondary objectives}

- Finding the direct and indirect factors causing drought and the influence of drought in agriculture in the study area

- Recommendingsuggestions to lessen the impact of drought in the study area.

\section{MATERIALS AND METHODS}

Both primary data secondary data were used for this study.

\section{Primary data}

Using simple random sampling technique, 40 percent of experience farmers were selected and questionnaires were distributed among them.

- Conversation

- Meeting with farmers

- 02 officials from Department of irrigation in Anuradhapura

- 02 officials from Agrarian Service Centre

- 01 official from Meteorological Department

\section{Secondary data}

Reports from Divisional Secretariat, District Secretariats, meteorological department, disaster management centre, newspapers, books, published researches and internet sources were used as secondary data.

\section{RESULTS AND DISCUSSION}

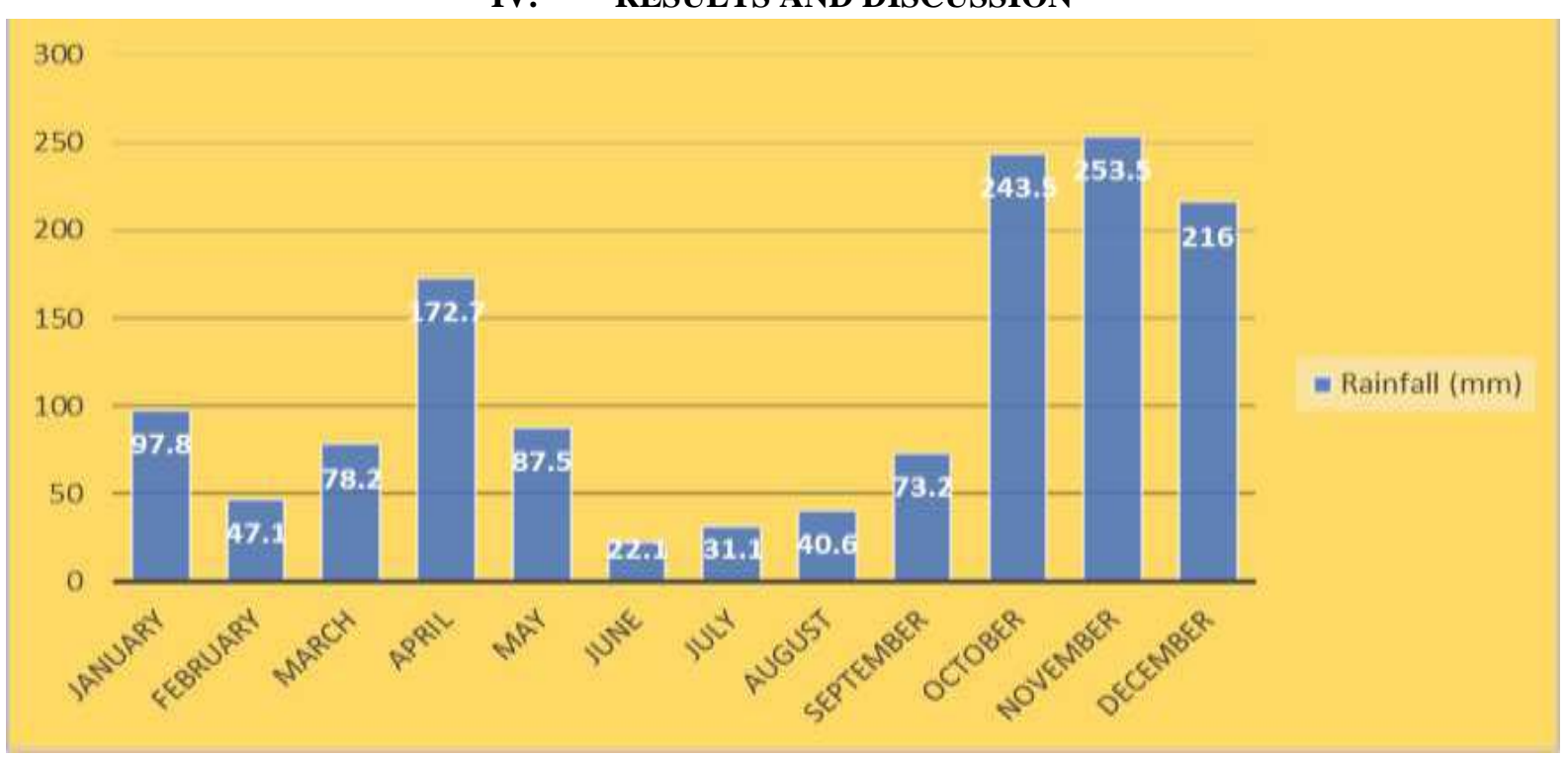

Fig.1: Monthly Rainfall of Anuradhapura District 1970 - 2009

Source: Meteriological department, colombo

Figure no: 01 shows the monthly rainfall of Anuradhapura District. Accordingly, Anuradhapura District receives more rainfall from October to December. The drought disaster affects in Anuradhapura in June, July and August.
The mid part of the year experience the drought highly. Thus, there is a need to be a preparedness in the middle of the month in Anuradhapura District. 


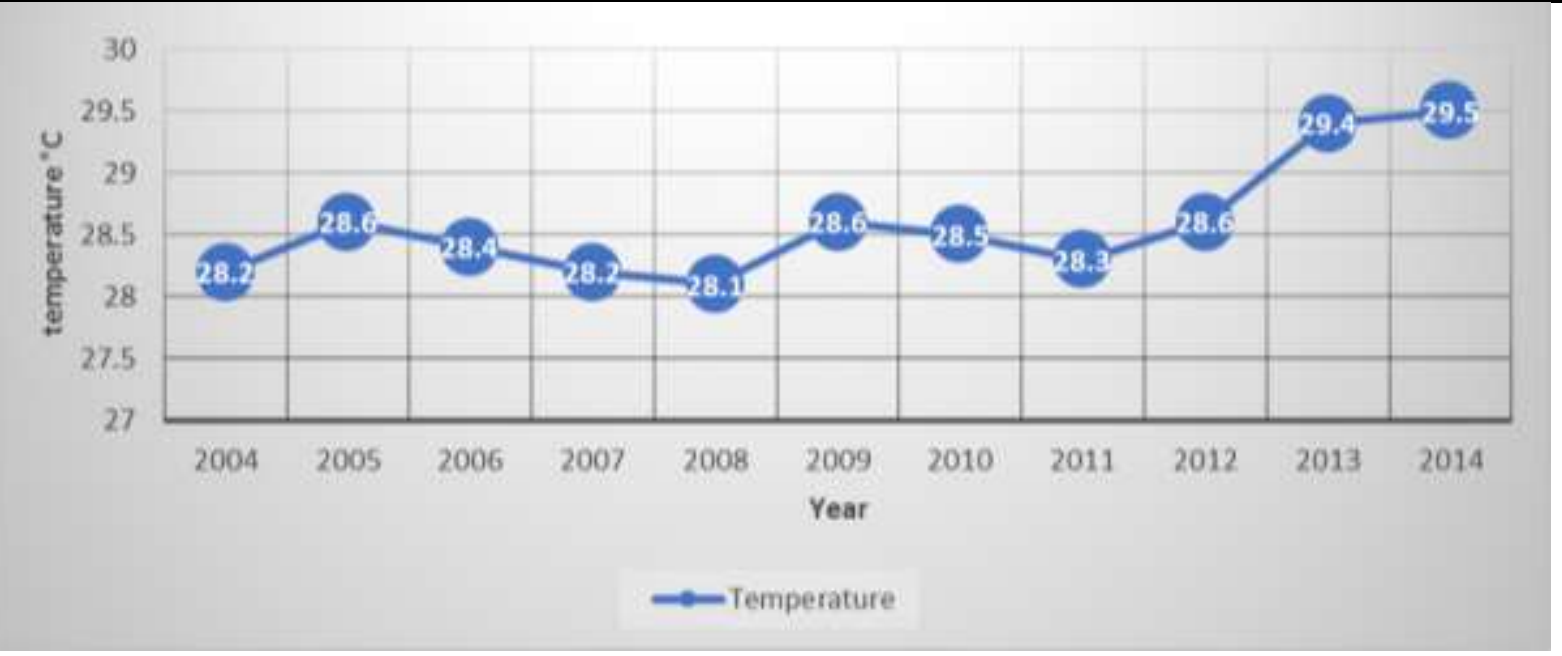

Fig.2: Annual Temperature of Anuradhapura District 2004 - 2014

Source: meteorological Department, Colombo

Figure: 02 shows the temperature trend of the Anuradhapura District. Temperature in 2004 has been registered as $28.2^{\circ} \mathrm{C}$ but in 2014 it has been registered as 29.5. It is evident that, the rate at which temperature had been increasing is a cause for the drought in Anuradhapura. Increasing temperature has caused the evaporation. Evaporation leaded to the increasing drylands in the study area.

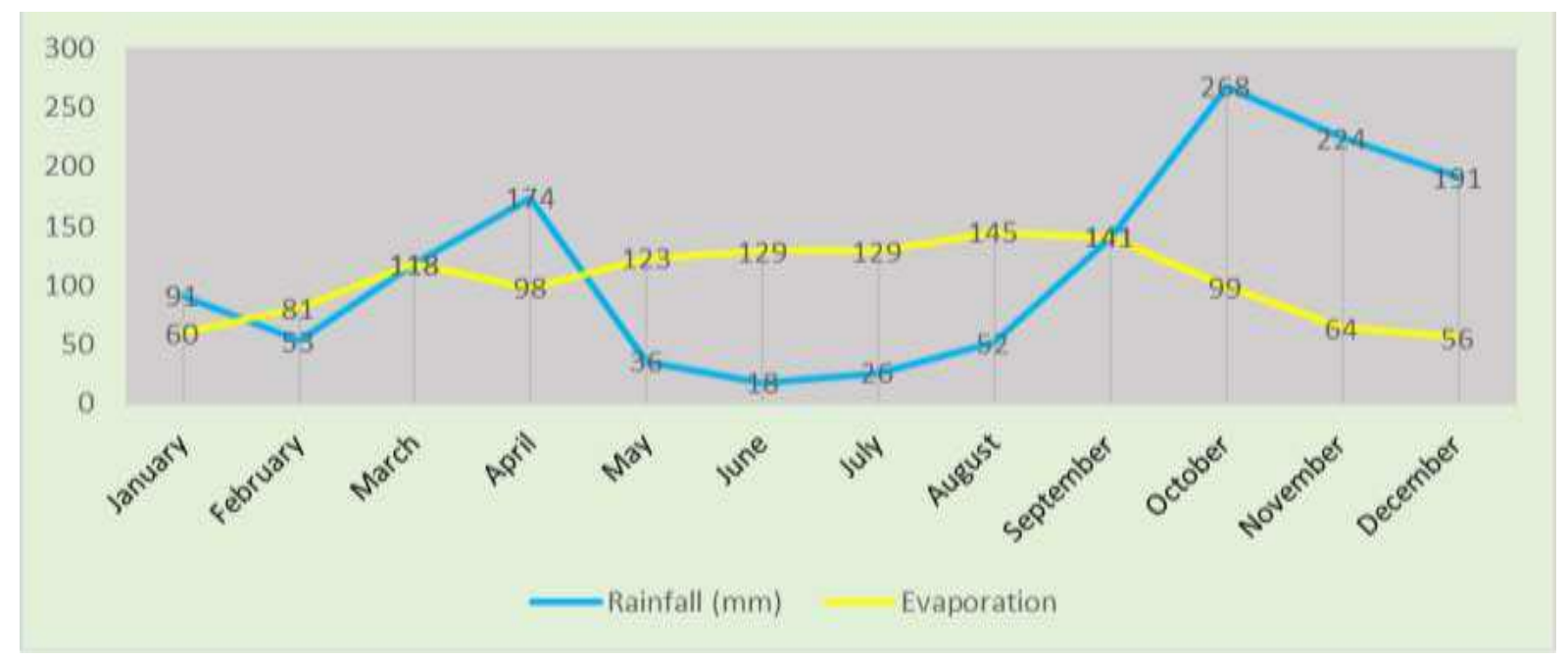

Fig.3: monthly water balance of Anuradhapura District - 2012

Source: meteorological department, Colombo

Figure: 03 shows the average water balance of Anuradhapura District. Decreasing influx of water has been registered from May to August. At the same time, the evaporation rate is high during this period. And also, increasing influx of water registered from October to December but evaporation rate is low. These are the periods of water availability in Anuradhapura District.

\section{Moving average curve}

With the help of MINITAB software, moving average curve and residual mass curve have been created using collected data. To figure out the condition of drought, 11 and 21 years' moving averages have been calculated.
To explain the condition of the drought in Anuradhapura District, 150 years rainfall data from selected stations were used. The highest rainfall has been registered as $2428 \mathrm{~mm}$ in 1957 at the same time, $741 \mathrm{~mm}$ rainfall in 1956 as a lowest amount of rainfall has been registered.

- 11 wet seasons

- 09 dry seasons

- 35 dry seasons

- 06 wet seasons

- 12 dry seasons

Comparatively, Anuradhapra District has experience more dry seasons than wet seasons. 
11 years' moving average curve

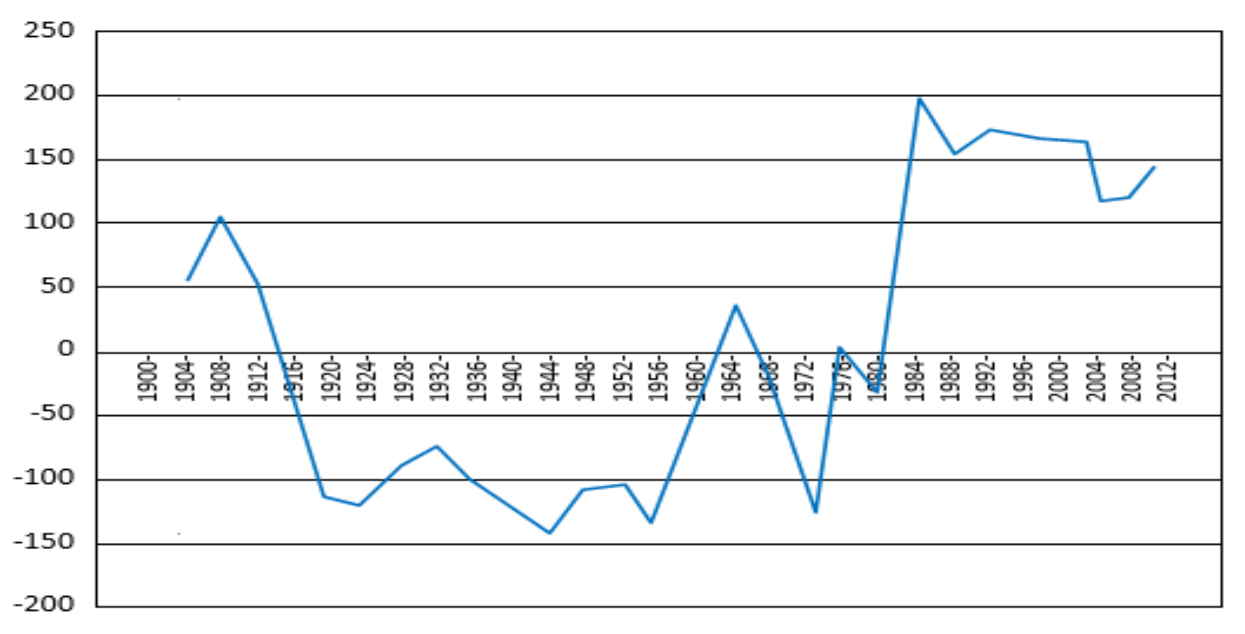

Source: meteorological Department, Colombo

21 years' moving average curve

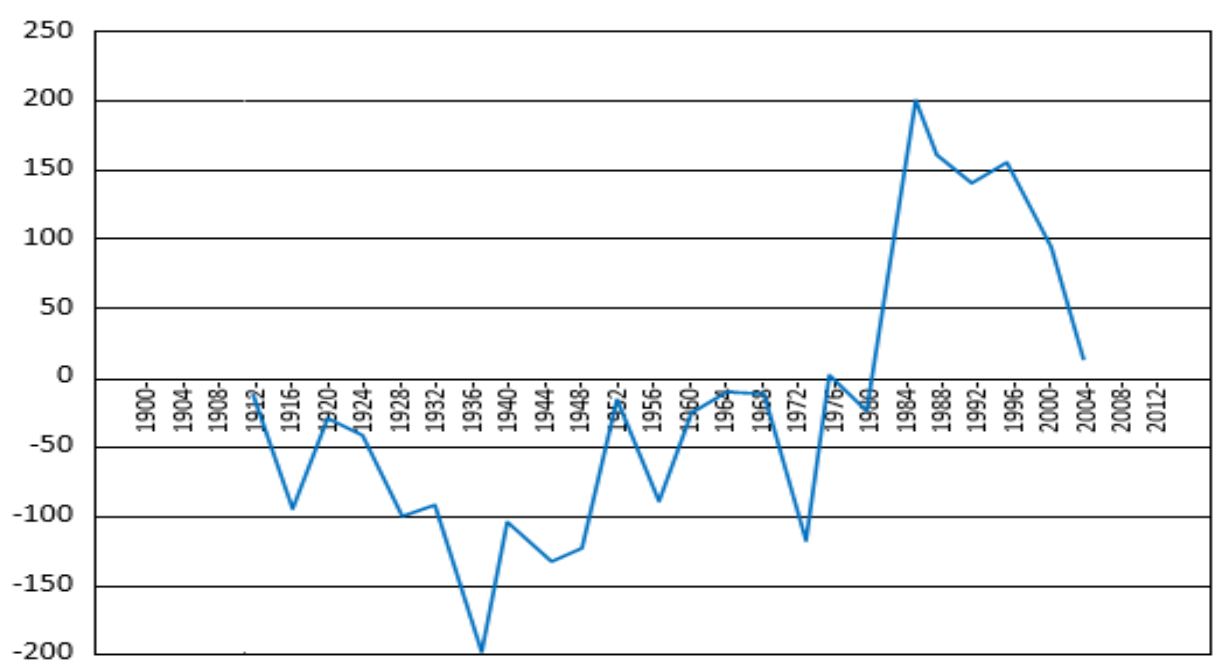

Source: meteorological Department, Colombo

The impacts cause by drought disaster have been listed as follow.

- Environmental impact

- Economic impact

- Social impact

Environmental impact

- Loss of soil fertility

- Loss of flora and fauna

- Drying water bodies

- Threats to the biodiversity

- Collapsing food chain

- Loss of ground water quantity

Economic impact

- Industrial activities have been affected in many areas such as brick production and fishing
- Increasing state coast. Due to the drought the government has to spend a lot of money for the rebuilding of the inhabitants.

- Due to the drought the income of the people by the tourist have been affected.

\section{Social impacts}

- Waterscarcity for drinking and agricultural purposes

- Dwindling freshwater fishery

- Diseases. Particularly, water borne diseases such as cholera and diarrhoea

- Poverty

- Loss of animal farming 


\section{RECOMMENDATIONS AND} CONCLUSION

\section{Recommendations}

Many recommendations have been suggested to control the impact of the drought in the study area.

\section{Before drought}

- Adopting rainwater harvesting systems during the rainy season

- To cut the water wastages

- Introducing water storing techniques among the inhabitants

- Using surface and groundwater in sustainable manner

- Controlling the deforestation

- Using seawater by desalination with the help of government

- Introducing waste water purification system

During the drought

- Supplying drinking water for the victims by bowsers. In 2014, clean drinking water was supplied to the inhabitants of Kepatikollawa

- Granting subsidies for the victims

- Changing the land use pattern in the study area viable to keep the water

- Assisting for the victims with the help of NGOs and government organizations such as local governments

\section{Post drought period}

- Project for the rehabilitation of hand pump tube wells in Anuradhapura and Pollonnaruwa.

- Taking actions to reduce the impact of drought in the study area

- Adopting cascade system for the water management

- Conserving the crop cover in the study area

- Educatingstudents to conserve water for the future generation

- Changing the crops viable to grow in less amount of water

- Identify the yearly drought prone areas in the study area

- $\quad$ Taking actions to construct small scale ponds to collect water.

- Proving awareness among people in the study area

\section{CONCLUSION}

According to the analysis, Anuradhapura District has been highly affected by the drought. The increasing temperature and decreasing rainfall caused the drought in Anuradhapura District. 114 years data clearly show the condition of the drought in Anuradhapura District. The agriculture of Anuradhapura District hasalso been affected due to the drought and the national paddy supply would be reducing if this condition continue.

\section{REFERENCES}

[1] Basnayaka, B.R.S.B. (2007) "Climate Change" National Atlas of Sri Lanka, survey Department of Sri Lanka, Colombo, pages 54 - 55

[2] Chandrapala, L. (1996), "Long-term trend of Rainfall and Temperature in Sri Lanka. In Climate variability and Agriculture" Y.P Abol, S. Gadgel and G.B Pand (Eds). New Delhi, India, Narosha Publishing House. Pages 153 - 162

[3] Climatological Water balance in Batticaloa Region', faculty of Arts, University of Jaffna, Vol.5 (iii), November 1993, 66 - 78. Cintanai.

[4] An Assessment of Rainfall Variability in the Mannar Region, Jaffna Geographer, Geographical Society, University of Jaffna, Vol. IX, No 3, 1994, 86 - 95

[5] District Profile, 2010, Anuradhapura, Sri Lanka

[6] Central Bank of Sri Lanka 2012. Annual report Statistical appendix. Colombo: Central Bank of Sri Lanka.

[7] National physical plan and project proposals, 2011 2030, Sri Lanka

[8] Reports of agrarian service centre - 2014

[9] Reports of Divisional secretary - 2012

[10] Reports of irrigation department - 2014

[11] https://www.nationalgeographic.org/encyclopedia/dr ought/ 